\title{
Toward A Broader Notion of Causation (and Technology) ${ }^{1}$
}

\author{
Peimin Ni
}

Modern technology has undoubtedly brought us conveniences and advantages that no previous generation had even dreamed of. Yet as it penetrates deeply and vastly into every corner of the globe and all walks of life in an amazing speed today, the overall quality of life is not getting better in a comparable degree. To the contrary, some very alarming phenomena disturb us more and more. The place we live is in many senses less like a home. Home does not refer simply to a place we reside or dwell. Home is an asylum, an environment that provides the subject with security, comfort, and a sense of mutual belonging (the subject feels that the place belongs to him/her and that he/she belongs to this place). Yet the place we live now is full of danger, more from the giant technology that we created than from anywhere else. Some have argued (Jacques Ellul and Lewis Mumford, for instance) ${ }^{1}$ that technology has been undermining the principles of cosmic order and become an autonomous force that alienates humans and even threatens the very existence of human beings. Others are more optimistic, and have more confidence in the merits of technology and the human ability in using and controlling it properly, but few would deny the need to take the concerns seriously and come up with some ways to cope with the problem.

The problem, however, is not merely the disastrous consequences of misuse and malfunctions of technology in the external physical world, as it is often conceived. It exists in our overall existential condition, including our subjectivity. Many scholars have pointed out that technology is more the symptom than the root of the catastrophic consequences, actual or potential. What Heidegger means by "the essence of technology is by no means anything technological," 2 is explained well by Lechtman and Steinberg. They point out unequivocally that

1 The paper is published in Technology and Cultural V alues on the Edge of the Third Millennium. Ed. by Roger Ames and Peter Hershock, Honolulu: The University of Hawaii Press, 2003, pp.188-205. 
[t] he rapid technological changes we currently living through are not the result of a technology run wild - free of the control of men, ... but rather an institutionalized form within a much larger cultural system. ... The fear and anxiety people feel and express about technology today, although real, are of course misplaced, but it is convenient to blame technology rather than to see it as symptomatic and expressive of value systems and orientations that characterize our world view. ${ }^{3}$

The worldview imbedded in technology, as Callicott and Ames put it, is "the Bacon-Newton complex of ideas-science as manipulative power over an inert, material, mechanical res extensa." 4 The project of dealing with the presence of rapid growing technology is therefore essentially dependent upon a reassessment and reconstruction of the worldview imbedded in it and the praxis defined by the worldview. Simply curbing the development or the application of technology will merely reduce the intensity of our problems but not solve them at any substantial level.

Based upon the above observation, this paper will focus on the notion of causation entailed in technology, one that I will loosely call "efficient cause." Heidegger, in his discussion of technology, pointed out the fact that

[f]or a long time we have been accustomed to representing cause as that which brings something about. In this connection, to bring about means to obtain results, effects. The causa efficiens, but one among the four [Aristotelian] causes, sets the standard for all causality. This goes so far that we no longer even count the causa finalis, telic finality, as causality. ${ }^{5}$

However, things that are more familiar now are not always things that were more obvious. ${ }^{6}$ If we take the general notion of cause in the sense of the Greek word that brings all the four Aristotelian causes together-aition, - that to which something else is indebted or responsible, ${ }^{7}$ we can find the notion of efficient cause is but one of many. I will compare and contrast the notion of efficient cause with a Chinese notion of cause which Joseph Needham calls "biogenerative," a notion in which things do not cause each other in a singly catenarian and particulate way; instead they respond and resonate to each other as interdependent nodes of a reticular and hierarchical cosmic order. ${ }^{8}$ I will suggest that we should move toward a broader notion of causation and a broader praxis (technology) as we synthesize the efficient and the biogenerative notions into a system with some further expansion in the fashion 
somewhat like what was proposed by Hua Yan Buddhism. Our notions of cause structure our life and our possibility. For this reason, this paper is no less a recommendation of how we should live our life and a practice of this kind of living in itself, than a descriptive analysis of certain particular views about the world and our practices.

\section{I}

Heidegger has insightfully identified a few important facts about the notion of efficient cause. One fact is that the objects of causal influence are taken as lumps of inert matter, with no will, no end or value in themselves. They are "standing-reserves,"9—-simply there waiting for humans to manipulate and use. This "matter" is the Cartesian body extended in a Hobbesian way to the entire universe, under which the whole world becomes a disenchanted mechanical aggregate of discrete entities, governed by neither God's will nor by any other spiritual ultimate.

"[] $\mathrm{t}$ is the theory about the nature of what one is working with," stated Mitcham, "that is a primary determinate of how one works, the structure of the working itself, although not necessarily what one works to do."10 The praxis of the efficient causation is very much structured by the notion of matter. Out of this concept of matter, people believe in no intrinsic value of things. Everything has value only so far as they are the objects of our will, as Kant puts it clearly. As a result of this notion, as soon as we can afford to, things are no longer fixed when they are broken; they are replaced even when they are not broken, but simply appear less appealing or less "efficient" compared to something newer. When we possess more, we have less that we really treasure. Everything becomes disposable. We force upon objects to satisfy what we want from them. We make our office buildings too cold in the summer and too warm in the winter! We let vegetables grow regardless of the season. Kant's claim that we are the legislators of our universe becomes literally true in the praxis. Even the aims of our working are strongly molded by the notion of matter, as the actions done on the basis of such a notion tend to be nothing but empowerment, excitement, convenience, overcoming, and dominance. Manipulative power becomes the paramount measure of superiority.

As a result, things "bite back," forcing us in constant vigilance against them or to exercise stronger control over them. It is true that we learn from catastrophes, and every catastrophe stimulates technological advances. The safety features of our cars and airplanes are now much more advanced than 
before. Whenever there is a problem or danger from technology, we expect a solution from newer and more sophisticated technology. But as Edward Tenner, the author of the book Why Things Bite Back, says, more and more problems turn to be chronic - less alarming but no less threatening (e.g. compare the Titanic with global warming). ${ }^{11}$

I wish Tenner could offer a clearer answer to the question "why things bite back" by pointing to the human attitude toward "matter," and its association with the philosophical notion of "matter" itself. The notion of "matter" as the object of efficient causation marks a fundamental difference between the notion of efficient causation in modern technology and the notion of efficient causation understood by Aristotle and other ancients who practice "techne." In this regard, the Chinese biogenerative notion is on the same side with Aristotle (and the opposite of Democritus, for instance). Both Aristotle and the ancient Chinese philosophers such as Daoists and Confucians take what we work with as living reality that has its own nature. To Aristotle, it is legitimate to talk about the telos or desire of the matter. While the word telos may suggest something that is designed purposively, and should be avoided, we may still differentiate purposive behaviors from behaviors that show ends (which may or may not be designed purposively). Ends (telos) "are characteristic of all kinds of things," says Francis Slade. Ends "exist independently of our willing them," while "purposes take their origin from our willing them."12 Ends are not intentional, and words that indicate ends have much wider application than to describe intentional purposes. In molecular biology, words that usually apply to human behavior are widely used to describe molecular interactions. Genes are described as being capable of "learning," making "recognition," "editing," "correcting errors," "desiring" certain intermediates, "avoiding" something else, etc. Some biologists have even gone so far as to apply words like "selfish" and "altruistic" to the behavior of genes. But those biologists argue that as long as they make it clear that their usage of those terms imply no intentionality, and are used strictly in behavioristic terms, it should do no harm. ${ }^{13}$ I think we can even argue that they should not only do no harm, but also be beneficial, as they will remind us that in our use of things, we must align our purpose congruent with the ends intrinsic to the things.

Though there is no strong teleological theory in Chinese philosophical tradition, the Daoist notion of ziran (自然 self so-ing) and the Confucian notion of xing (性 nature) are close matches. Things are not considered as dead lumps of matter by Confucians and Daoists. They have their own nature which determines their "likes and dislikes" (as water "likes" to go down). Further more, both the Confucians and the Daoists take the universe as an organic system, in which objects participate in the 
creation of the world in a web of generated/generating relationships, and therefore are not merely the objects of prediction and control. Things have to be respected as what they are and where they belong, and not to be forced against their own nature. "The world is a sacred vessel," says Laozi. ${ }^{14}$ "It should not be acted on. He who acts on it harms it. He who holds on to it loses it" (chpt. 29). Out of this understanding, the praxis from the biogenerative model aims at increasing strength, fulfillment, perfection, and harmony. "[Dao] produces but does not take possession of what it produces. It acts but does not rely on its own ability. It leads but does not master. This is called profound and secret virtue" (chpt. 51). The same lines appear in chapter 10 with the subject the sage rather than the Dao, indicating that it is the kind of virtue that the sage models after the Dao. These teachings showed clearly how the Daoists understood the objects of our causal influence.

Tenner is very close to that biogenerative structure of praxis when he discusses the possible solutions for the problem of revenge from things. He says that one promising attitude which he is unable to find its rightful name is the substitution of cunning or finesse for the frontal attack.

"Finesse means abandoning frontal attacks for solutions that rely on the same kind of latent properties that led to revenge effects in the first place. Sometimes it means ceasing to suppress a symptom. In medicine, finesse suggests closer attention to the evolutionary background of human health and illness, to the positive part that fever plays, for example, for fighting infection. At other times, finesse means living with and even domesticating a problem organism.... In the office finesse means producing more by taking more frequent breaks and conveying more information by, for example, limiting rather than multiplying color schemes. In construction, finesse means allowing skyscrapers to sway slightly in the wind instead of bracing them to resist it. On the road finesse means a calmer approach to driving, improving the speed and economy of all drivers by slowing them down at times when impulse would prompt accelerating. ...".15

What is common to all these suggestions is to follow the nature of the objects that we deal with and let the best results be the natural outcome of their own nature rather than something forced upon them. This is also the advice from the biogenerative model. The examples Tenner uses exemplifies the Daoist notion of mmwei (无为, non-action). The best way to act is by "non-action"—no fighting against nature. Let your action be like water flowing down or a plant growing up, effortless. The best swimmer is one who does not fight water, to the contrary, water becomes his condition to swim freely. "Let your mind 
wander in simplicity, blend your spirit with the vastness, follow along with things the way they are, and make no room for what is merely personal — then the world will be governed," says the Daoist Zhuangzi. ${ }^{16}$

\section{II}

Another point brought up by Heidegger is that from the perspective of efficient causation objects are always quantifiable and calculable. Modern physics picture nature as something "identifiable through calculation and that it remains orderable as a system of information."17 "[A]ll events, if they are to enter at all into representation as events of nature, must be defined beforehand as spatiotemporal magnitudes of motion." "But mathematical research into nature is not exact because it calculates with precision; rather it must calculate in this way because its adherence to its object-sphere has the character of exactitude. The humanistic sciences, in contrast, indeed all the sciences concerned with life, must necessarily be inexact just in order to remain rigorous. A living thing can indeed also be grasped as a spatiotemporal magnitude of motion, but then it is no longer apprehended as living." ${ }^{8}$ However, according to the modern physicalistic-mechanistic model of efficient causation, what is really alive? Everything is governed by the physical laws of nature and eventually all can be reduced to local motions of matter.

The point is related to the search for repeatability or regularity. Because regularity provides means for controlling results, it is quite natural that scientists will be motivated (and encouraged by fundings) to find correlations. Post Galileo in sciences and Hume in philosophy, scientists are no longer very much interested in understanding "why" for scientific explanation. They are satisfied with discovering and describing "how" states of affairs are correlated with one another. Quantification of objects makes the observation and description of regularity much easier and more feasible than trying to understand objects holistically. There is a great advantage in doing that, but the price we pay is that, as a result, the realm of genuine events in which uniqueness and concreteness are found is reduced to the status of mere accidents and chances, dealt away with by statistics.

D. Athearn calls this Scientific Nihilism, because there is no more narrative explanation or understanding of the world in this system of knowledge. The status of scientific theory depends solely 
on its problem solving and prediction power. ${ }^{19}$ The way that scientists use to transcend mechanical causation is to hide themselves in the world of mathematical formulae, so that they do not have to talk about whether a correlation is mechanical or not. There is no more distinction between causal and noncausal sequences. The "real connections" between objects or events become mystery. ${ }^{20}$ Indeed, how can that not be the case after Hume? When the theory is translated into praxis, we see that for the consumers of technology, all they care about is the intended results. To borrow an example from Peter Caws, a person who starts his car in a cold morning may be no less blind than a person in a primitive tribe who dances for rain as to the mechanics of how their particular rituals work (or do not work) sometimes. ${ }^{21}$ (One difference is that the dancer for rain would have a sense of awe and reverence for the "god" that he prays to for help, but the man starting the car would typically take the respect for the car to be totally irrelevant.)

David Griffin is right when he points out that the regularity view actually reflects "the assumption that things are essentially independent of their environments." 22 The assumption is a natural outcome of Cartesian rationality, of which the basic feature is the search for clarity and distinctness. It inevitably results in atomistic "decontextualism," as Fred Dallmayr puts it. ${ }^{23}$ An individual being is distinct from other individuals as well as non-human objects, the mind is distinct from the body, the intellect is distinct from other parts of our mind. What is left finally is the disembodied and dispirited intellect, confronting the entire world as the other equally dispirited material body. ${ }^{24}$ The metaphysical separation of self and non-self and the accompanying conception of rationality are what are fundamentally responsible for anthropocentrism and for the opposition between human beings and the "matter." Some philosophers have tried to rid anthropocentrism by enlarging the circle of their moral consideration, from considering nature as merely instrument for satisfying human desires to considering the nature as a participant of human intrinsic value (Anthropocentric Reformism); from granting moral consideration to animals (animal liberation) to all ecological beings (Ecocentrism). The entire movement involves a paradox because it is based on a deep metaphysical conceptual framework, which separates humans from everything else, and is therefore anthropocentric in its very nature. It is therefore unable to justify assigning intrinsic moral values to non-human beings.

Mathematical regularity further entails standardization of our causal activities. Though Alvin Toffler tried to argue that technology may provide more variety and multiplicity, ${ }^{25}$ yet the fact that communication and service serve essential roles in technology requires that standardization and 
monolithic be the norm rather than the exception, and most of the non-technological differences become mere appearance. Recent dominance of Microsoft in the computer business is an example. Whether you are Chinese or Italian or Egyptian, you are forced to use English to operate your machine, and everyone is forced to upgrade their PC to make it compatible with Windows 98 or something of this sort in order to survive.

The biogenerative notion of cause shows opposite features. There is no reduction of things to numbers, nor separation of the self and non-self or the manipulator and the manipulated. Harmony and mutual dependency between particular objects are always stressed. Seeing things concretely and holistically in terms of their interconnection and interdependence is considered wisdom, and acting accordingly is considered rational and a way to gain strength. In Chinese philosophy, tian ren he yi (天人合一, the unity between haven and human) is simultaneously a descriptive insight—metaphysics (事理), an ideal state to reach—value (境界), and an instruction for a better life-methodology (功法).

According to the biogenerative model, objects have their own particular natures and they are all parts of a web formed by interdependent nodes, without a weaver, resonate and respond to each other. ${ }^{26}$ Not only the nature of the object itself, but also the place it occupies in a web, determines its causal role. The interdependence is so important to the understanding of each particular that detached from it, one sees an abstraction, not the particular anymore. Within complicated and ever changing situations, repeatability can only be relative and limited. If we further include people's mental states and cultivation as parts of the causal web, the chance of having repetition is reduced greatly. This metaphysical outlook creates difficulty for ancient Chinese medicine and related practices to be recognized and accepted by the modern mind as "credible" or reliable, and yet exactly in those areas the metaphysics is closer to our real experience. Things and their relations are much too rich to be merely understood in terms of quantifiable regular sequences of events.

It is true that China did not develop modern science and technology, not even the notion of scientific laws. But that does not mean it did not have any notion of cosmic order. The Daoists chang [常, constancy] and the Confucian $l i$ [理, cosmic principle] are both about orders of the nature as well as of the human society. Both Daoists and Confucians had observations about sequential regularity. Take a few examples from the Dao De Jing: 
"He who has lavish desires will spend extravagantly, he who hoards most will lose heavily."27

"Violent and fierce people do not die a natural death."28

"Great wars are always followed by famines."29

'Take also a couple of examples from Confucius' Analects.

"Those who are ren (benevolent) have longevity."30

"A ruler who governs his state by virtue is like the north polar star, which remains in its place while all the other stars revolve around it." 31

Those are not much different from the regularity entailed in efficient cause, just that the causal links in those observations can hardly be quantified as local motions of bodies, much less accurately. But there is another kind of order entailed in the notions of chang and li, which C. G. Jung calls "synchronicity,"32 and it is more characteristic to the biogenerative way of thinking. The order is about patterns of coincidence. Jung characterizes the order in this way:

How does it happen that A', B', C', D' etc., appear all in the same moment and in the same place? It happens in the first place because the physical events $\mathrm{A}^{\prime}$ and $\mathrm{B}^{\prime}$ are of the same quality as the psychic events $C^{\prime}$ and D', and further because all are exponents of one and the same momentary situation. ${ }^{33}$

Notice that the pattern of explanation from this model is very different from those that result from the model of efficient cause. The explanation is not that there is a law governing the sequence of events of the type A, B, C, and D; it is that all A', B', C', and D' have the same quality, and that is because they are all expressions of the same momentary situation. The Chinese had accumulated an impressive stock of empirical observation to form many generalizations about this kind of synchronic order, and Chinese medical practice and its development are to a considerable degree based on these generalizations. It is typical for a Chinese doctor to link, say, a rare abnormality of a woman's menstruation to the color and texture of the patient's tongue, and reason that, since the particular appearance of her tongue usually comes with lung problems, so the lung may be the cause (本, root) of both symptoms (末, the tips of a plant). The prescription would then be some herbs that are supposed to adjust the lung. The doctor may 
also infer that since lung problems usually come with excessive worry or depression, so the prescription will then also come with an advise that she should avoid being worrisome, and maintain her mental peace, which can further imply adjustments in other parts of her life. The Chinese classic of medicine Huang Di Nei Jing 黄帝内经 is full of descriptions of these synchronic patterns of coincidences, and medical practices based on these patterns are often amazingly effective!

The Daoists did further generalizations about synchronic orders and they parallel general laws of physics in their simplicity and inclusiveness:

Being and non-being produce each other, difficulty and easy complete each other,.... ${ }^{34}$

When the great Dao is abandon, there are benevolence and righteousness. When knowledge and wisdom appear, there is hypocrisy.... ${ }^{35}$

Being all-embracing, he is impartial. Being impartial he is kingly (universal). Being kingly, he is one with Nature. Being one with Nature, he is in accord with Dao. Being in accord with Dao, he is everlasting, and is free from danger throughout his lifetime. ${ }^{36}$

We may easily see the more generalized formula from the last quote: "Being all-embracing correlates with being everlasting and being free from danger."

Following these principles, the ancient Chinese always watched carefully that they put themselves and the things they deal with within a whole picture, and watch the whole picture for signs and indications that they need to make adjustments.

Observations of synchronic order enable people to make inferences much wider than observations of linear regularity would allow. Our example of Chinese medicine illustrates this point. The doctor has never seen any case like the woman before, yet she is able to make a prediction based on previously observed coincidences. But the chance of having an accurate prediction on the basis of synchronicity is not as high as predictions based on regular sequence of events. As a broad scale synchronic correlation includes the entire cosmic situation, it is hard to say what was actually making the difference when some expected pattern failed to show up. For the same reason, it is hard to reproduce 
any event in a similar cosmic situation, and therefore experimental tests of the coincidences would obviously be more difficult to conduct than in the case of testing isolated sequential orders. Overall, we might say that synchronic orders are less "accurate" mathematically, but nevertheless we can make them as "rigorous" as the natural orders allow us to.

\section{III}

Still another important point made by Heidegger's previously quoted work is that the world view and the praxis of efficient causation also turn human beings ourselves into objects, as standing-reserve. "[T]he current talk about human resources, about supply of patients for a clinic, gives evidence of this."37 Technology was an affirmation of human being, an emancipation from the medieval total denial of individuals and their material needs. It increased the human power and expanded our realm of freedom. But ironically, we became objects of technological manipulation as well. When I took the cable car to the top of mount Tai in just a few minutes, I wondered whether I consumed technology or technology consumed me-because it almost deleted the height of the mountain, which is the primordial reason that it became historically and culturally significant. Tourists around the world are like birds in gilded cages, they sit in air-conditioned luxury buses and stay in five star hotels. Inside of those spaces, you do not feel the difference between being in Manhattan and being in the Gobi Desert. They look at the places that they visit through tinted windows or camera lenses. Films and tapes replace human eyes and brains to perceive what is out there. As I fly over the sky in an airplane and look down from it, I feel as if down there is a different world, so alien to me. Our world is like a net, and we are bugs on the net destined to move along the linkages defined by technology. We seldom touch the earth (most of the time we touch floors, not the earth).

Also ironically, in proportion to the increase of our manipulative power, we become increasingly vulnerable! We rely upon the things we create so much that we are at their mercy-imagine one day that our electricity supply or gasoline supply is cut, or our computer systems are all down, what America would be like! The anxiety caused by the Y2K bug would make ancient people laugh! Though the word "technology" is derived from the Greek word techne and should rightfully be a genus of techne, it is now actually the opposite of it. The ideal of technology is to become less and less demanding on the human part. The control act of using technology should require least amount of experience or training or cultivation from the consumer. Instead of training a person to swim so that one can be so well 
aquatinted with the water that one forgets its existence while being in it, modern technology would invent devices that enable one to flow or even fly on the water without knowing anything about water. Automatic cameras make fewer people know how cameras capture pictures. Calculators make many people unable to calculate the simplest math problems in mind. Spelling check functions in our computers make us less capable at spelling correctly. Technology should free people from tedious labors and provide more time for people to develop themselves as human beings, but actually it often ends up degenerating people to lower levels of sophistication, with less understanding of the world around us, and less capable of dealing with revenges from nature and less capable of living a life without having to deal with technological problems.

One thing that is wrong behind all these phenomena, in addition to the problems that I tried to identify in the previous sections, is that modern technology, based on modern science, is reductionistic. It "inclines us to understand the human in terms of the non-human."38 Even though people seldom seriously deny mental causation and the interaction between the mind and the body, at the very fundamental level it is still quite foreign to our notion of efficient cause that our mind is able to affect physical processes in any direct way. The tendency to reduce everything to physical is so strong that the belief in genuine non-physical existence is almost synonymous to being "unscientific." Based on reductionism, the praxis of efficient causation becomes by and large mechanical. The causal agent exerts his causal influence to an object by forcing his power upon it from outside, pretty much in the way that one assembles parts of a machine together or moulds clay into a figure. Aesthetic, moral, and spiritual cultivation is seen as satisfaction of our mind rather than activities that can be really effective in bringing results. The previously mentioned phenomena of antagonism between human and non-human come from the antagonism between our genuine self which is isolated, disembodied, and the materialized, physicalistic self that we created along with the creation of the world of technology. Everything we need is reduced to what is materialistic, and in the end we ourselves become materialized. "I was there" becomes "I was physically there," "I know how to ..." becomes "I have the devise to ...," and "I am sick" becomes "the medical tests show abnormal results."

The biogenerative model does not entail such reductionism; to the contrary, everything is viewed as having its own life and its own inclination. There is also no sharp distinction between the mind and the body or the reduction of the mental into the physical. Consequently the causal influence of the biogenerative model works differently. The effect grows out from within, as a plant grows out of a seed. 
The model suggests a causal praxis that requires the agent of cause to cultivate oneself, and ideally, to cultivate oneself so well that one can generate the intended effect effortlessly. The agent helps the object to "reveal" what is in it, and at the same time merges oneself with the object in bringing out the result. This kind of praxis demands more from the subject—-to understand the objects and their relationships with other things around, including ourselves, and to tune one's own disposition so that the best action can happen with the least effort, without any obstruction. Zhuangzi describes how a master woodworker would fast for seven days before he makes a bell stand, in order to calm down his mind. (When I do my calligraphy, I sometimes use a bottle of beer instead, as it works faster. ()) After that the woodworker goes to the mountain to examine the natural formation of trees. When he finds a tree in which he can see a bell stand there, he would then lay his hands on it. "It is simply to match up what is heavenly with what is heavenly," - the nature of the tree and his own unobscured nature. ${ }^{39}$ Zhuangzi's story about a cook who cuts oxen so skillfully as if he were dancing effortlessly also shows how important it is to cultivate oneself, and how, in the end the cultivation leads to the unity between the self and Heaven. These stories illustrate well how the ancient Chinese were able to create artifacts that are at amazingly high levels of perfection, like the Shang Dynasty bronze vessels (Shanghai museum has an impressive collection of these vessels), though the stories also illustrate well how this kind of praxis is unrealistic and unsuitable for today's mass production.

One thing that deserves our special attention is that the cultivation required by the biogenerative model often involves moral cultivation, not merely technical skills and cognitive understanding. The distinction between value and fact is totally foreign to Chinese philosophical traditions. For Confucians and Daoists, to be moral is literally a technique (though not to be simply reduced to technique) for the best life, for obtaining optimal subjective condition and for achieving a harmonious relationship and interaction with one's surroundings, and even for gaining extraordinary abilities and visions. Ancient Chinese literature is full of these kind of statements, and we have no reason not to pay attention to these statements which were written by otherwise very intelligent people. Mencius, for instance, claims that the $q i$ (vital energy) nurtured by righteousness can be so vast that it can fill the Heaven and the earth, and the morally well-cultivated person can find a myriad of things all at his disposal. ${ }^{40}$ This is another fascinating feature of the biogenerative model, though a draw back is that it is not easy to implement into effective use. 
Chinese tradition has been mainly considered as one that values life, contentment, virtue, peace, but not effective causation. ${ }^{41}$ This kind of picture entails a misconception that the Chinese tradition has never been seriously interested in leading to practical results. We have seen that this is not the case. The Chinese tradition has a different notion of cause and related to it is a different kind of praxis, which is effective in its own terms. But the notion and its praxis are indeed quite different from the efficient causation that is dominant today. Without sharp separation between the self and the non-self, and without reductionism, the theory and its related praxis are friendly to the environment and to the wellbeing of humans. It is tragic that China is now one of the countries that have the worst environmental crisis. If China could stick up to its own philosophical tradition, the country would be much more human friendly in some ways. But of course, if it were the case, it would then be unable to enjoy the conveniences and excitements that the rest of the world is able to enjoy. Realistically, it does not seem to be possible given the penetrating material force of modern technology. Even if the country were able to resist technology for a little while, it would soon put the nation in a very disadvantageous position to confront the aggressive external forces. That is exactly part of the story of China in the past two hundred years. The question is, what should we do?

People in technologically advanced countries today are less likely to react like the engineering faculty at the University of Michigan back in 1980, when they abolished their Humanities Department's annual lecture series on "Technology and Values" because it sponsored a symposium on "Technology and Pessimism," and eventually closed off the Humanities Department itself. ${ }^{42}$ Nor will people in less technologically advanced countries react like the alleged Roman Emperor who, upon hearing that someone had invented unbreakable glass, said "Oh, put him to death."43 The enormous contributions that modern science and technology has made to human beings hardly needs verbal defense, and the presence of it is simply too powerful to even speculate realistically about how life would be better off without it. The fact remains true that technology and its underlying notion of causation are being introduced to every corner of the world as enlightenment, with irresistible material force and seductive colors. But as we have seen, the problems related to technology do not come from technology itself; they come from the imperialistic dominance of technology and the underlying notion of causation, which in turn come from our deep notion of rationality. It is neither possible nor smart to reject the Trojan horse of modern technology. A better solution is to digest it and go beyond it by overcoming its limitations! 
An inspiring example of such an effort for getting a broader notion of cause and related praxis is found in the philosophy and practice of a Chinese Buddhist school, Hua Yan 华严, typically attributed to its third patriarch Fa Zhang (法藏 643-712). Fa Zhang was able to synthesize the Buddhist concept of causation — dependent origination — with the Chinese biogenerative model of causation ingeniously into a hierarchic system of causation. According to the summary given in English by Takakusu, ${ }^{44}$ the system consists of four kinds of courses: karma causation (业感缘起), causation by the ideation-store (赖耶缘起), causation by thusness (真如缘起) and Dharmadhatu causation (法界缘起). The four causes are related in such a hierarchy that each of the succeeding ones is on a level of understanding and practice that surpasses the previous ones, and eventually all the previous levels are incorporated in the highest one.

It is beyond the scope and intention of this paper to accurately interpret and make sense of the very unusual philosophical theses of Hua Yan Buddhism. What I would like to do here is to draw some helpful inspirations from the overall structure of such a theory and venture a free elaboration on the basis of the Hua Yan theory of causation.

The first one, karma causation or causation by action-influence, is about the mutual dependent arising of actions and reactions. When viewed from the hierarchic structure of causation, this is the most vulgar form. Most people are just in a certain action-influence relation without much understanding or self-awareness. The actions by people on this level can be more toward the physicalistic-mechanical efficient causation model or more toward the biogenerative causation model. Because they are not reflective and have no comprehension of their own praxes, individuals may feel as if they have no control over their own destiny; benefits and detriments of the praxes may fall upon them like a matter of luck.

The immediate way to go beyond the "karma" level is to make reflections about one's own notions of causation and the praxes molded by them. That reflection leads us to the second level—an understanding that all the limitations and problems are rooted in our subjectivity, our "storehouse of consciousness." The second level causation takes the mental volition as what is behind and more fundamental to the publicly observable phenomena. At this level, one understands that technology and 
techne are the symptom and expressive of something deeper in our mind; one starts to examine the notions of cause and can see their connections to different kinds of praxes. The reflections in the previous sections of this paper are exactly this kind of activity. If they were effective, they ought to lead the author and the readers to link their praxes with their philosophical subjectivity more consciously and self-reflectively. People on this level achieve a greater control of their own praxes than they were at the first level.

The third level, causation by thusness, goes deeper into the very nature of the person-thusness, the Dao, or simply the Ultimate. It is from that nature of us which is beyond any form and any description that the transforming phenomena (including consciousness and deeds) arise. Whalen Lai speculates that Fa Zhang's idea of causation by thusness is influenced by Daoism, as the Dao is said to be beyond form and description and yet it is the origin of everything. ${ }^{45}$ Lai also speculates that from an analogy that $\mathrm{Fa}$ Zhang uses_-water being the cause of wave-it bares resemblance to the Aristotelian material cause. ${ }^{46}$ The "material" in the Buddhist theory is the pure nature of the person, which in turn is the origin of the mind and the overt actions. At this third level, one digs even deeper into the fundamental philosophical rationality, and finds the philosophical foundation of which the second level philosophical reflection is the praxis_-as how one thinks is a cause of one's thoughts. The person who understands our nature to be formless Dao, or thusness, knows that separation is only relative and so even the distinctions between the agent and the objects, the cause and the caused, the efficient and the biogenerative models should be surpassed. When the person reaches an understanding of what she ultimately is, she will structure her activities accordingly. Zhuangzi's following story, in my opinion, illustrate a man at such a level:

Zigong saw a man who was going down into a tunnel that lead to a well, and fetching water with a jar to water his vegetable. Zigong said to the man: "There is a kind of machine by which you can water a hundred vegetable beds in one day. It takes little labor and get much done. Why don't you use that?" The man answered: "When you have a machine, you have machinery affairs; when you have machinery affairs, you have mechanical mind; with a mechanical mind, you do not have a pure mind; when you do not have a pure mind, your spirit will not be tranquil; and if your spirit is not tranquil, Dao will not be there. It is not that I do not know about the machine, it is that I am ashamed of using it. ${ }^{47}$ 
This is a man who "knows the white but stays with the black" (知白守黑), ${ }^{48}$ —with "the white" signifying the appearance, the revealing of the potentials of objects, etc. and "the black" signifying the very essence of the self, the Dao, the source of life. It is also a level that is religious or spiritual, as one transcends the immediacy of ordinary experiences and starts to live in the realm of the ultimate.

While some people may call the man who "knows the white but stays with the black" enlightened, but from the perspective of Hua Yan Buddhism, it is still not the highest level. The final level, Dharmadhatu causation, or "the Universal Causation of the Realm of Dharmas (elements of existence)" is the "fundamental concept" that "the whole Hua-yen philosophy centers around."49 At this highest level, the biogenerative notion of causation is not only incorporated into the Buddhist idea of dependent arising, but also pushed to its logical extreme, because underlying this concept is the idea of interpenetration and mutual identification of everything. According to this theory when one dharma rises, all dharmas rise with it and vise versa. To use the classic analogy, it is like in a hall of all mirrors, what is in one mirror is simultaneously in all the other mirrors, and what is in all the other mirrors is in each mirror. In that sense everything is the cause of itself and the cause of everything simultaneously. Yet at the same time it is also a state in which one will finally find "shi shi wu an" (事事无碍 no obstruction). That is to come back from the ultimate to the world of ordinary objects and find no obstruction in moving around. At this level, one does not have to stay in the "dark" (hide in the ultimate) to keep pure. One can be in the middle of a noisy city, using equipment of modern technology, and yet not be affected by the mechanical mind, nor will harm anything in using machinery. This is a point that Daoism and Confucianism both aim at - It is the level of being one with the Dao, participating the Dao in creativity. It is the level of "tian ren be yi" (天人合一 the unity between human and heaven), the level of "the myriad things are all here in me,"(Mencius) and the level of "you yu yi" (游于艺 take excursion in true artistic expression). ${ }^{50}$ One who is at this level can affect everything by her activities, while she is affected by everything simultaneously. Yet as she understands that her own nature is pure (Dao, thusness) nothing will be the opposite of the self. The otherness is no longer something external, to be used, overcome, or dominated; it is part of the self in the sense that one actualizes and transforms oneself through her encounter with the other. This kind of causation is also the highest level of achieved ability. The person on this level is not blindly indulged into this existential condition; she is able to take control of and develop her full potentiality by taking advantage of the interconnectedness of everything. Interestingly enough, it coincides with Heidegger's view that the solution to the problems of technology 
requires a return from technology to techne, to poetic activities. ${ }^{51}$ At this level, one's causal activities should be artistic and poetic, the world will be re-enchanted by such activities, and we will feel much more at home living in the global village linked together with this broadened technology.

\section{Bibliography}

Adas, Michael 1989: Machines as the Measure of Men - Science, Technology, and Ideologies of Western Dominance, Ithaca and London: Cornell University Press.

Athearn, Daniel 1994: Scientific Nibilism — On the Loss and Recovery of Physical Explanation. Albany, NY: SUNY Press.

Bugliarello, George and Doner, Dean B. 1979: ed. The History and Philosophy of Technology, Urbana Chicago: Univ. of Illinois Press.

Callicott, J. Baird and Ames, Roger T. 1989: Nature in Asian Traditions of Thought, SUNY Press.

Chan, Wing-tsit 1963: A Source Book in Chinese Philosophy. Princeton, NJ: Princeton Univ. Press.

Cheng, Chung-ying 1976: "Model of Causality in Chinese Philosophy: A Comparative Study," Philosophy East and West, Jan 1976, pp. 3-20.

Dallmayr, Fred 1996: Beyond Orientalism, Albany, NY: SUNY Press.

Dawkins, Richard 1981: "In Defense of Selfish Genes," Philosophy, vol. 56, 556-73.

Defoort, Carine, 1997: "Causation in Chinese Philosophy," in A Companion to World Philosophies, ed. by Eliot Deutsch.

Dickinson, Goldsworthy Lowers 1904: Letters from a Chinese Official: Being an Eastern View of Western Civilization. New York.

Ellul, Jacques 1964: The Technological Society, trans. John Wilkinson, New York: Knopf.

Ezrahi, Yaron et al. (ed.) 1994: Technology, Pessimism, and Postmodernism, Dordrecht; Boston: Kluwer Academic Publishers.

Griffin, David, 1996: "The Reenchantment of Science," in From Modernism to Postmodernism: An Anthology, ed. Lawrence Cahoone, Cambridge, MA: Blackwell.

Hassing, Richard F. 1997: "Intelligibility of Human Experience," in R. Hassing ed. Final Causality in Natural and Human Affairs. Washington D.C.: The Catholic University of America Press.

Heidegger, Martin, 1977: The Question Concerning Technology and Other Essays, trans. by William Lovitt, New York, NY: Harper \& Row, Publishers, Inc. 
Jung, C. G. 1950: "Foreword" for the Richard Wilhelm trans. The I Ching, Princeton, NJ: Princeton University Press.

_ "Synchronicity: An Acausal Connecting Principle," in The Structure and Dynamics of the Psyche (Coll. Works of C. G. Jung, vol. 8)

Lai, Whalen 1977: "Chinese Buddhist Causation Theories: An Analysis of the Sinitic Mahayana Understanding of Pratitya-samutpada." Philosophy East and West, 27, J1 1977, pp. 241-264.

Marx, Leo 1994: "The Idea of 'Technology' and Postmodern Pessimism," in Ezrahi et al. (ed.) 1994: Technology, Pessimism, and Postmodernism, Dordrecht; Boston: Kluwer Academic Publishers.

Mitcham, Carl 1973: "Philosophy and the History of Technology," in Bugliarello and Doner ed. The History and Philosophy of Technology, Urbana Chicago: Univ. of Illinois Press, 1979.

Mumford, Lewis 1970: The Myth of the Machine-The Pentagon of Power, New York: Harcourt Brace Jovanovich.

Needham, Joseph 1956: Science and Civilization in China, vol. 2(?) Cambridge: Cambridge University Press,

Ni, Peimin 1996: "A Qigong Interpretation of Confucianism," Journal of Chinese Philosophy, no. 23, 79-97. 1999: "Confucian Virtues and Personal Health," in Ruiping Fan ed. Confucian Bioethics, Dordrecht/Boston: Kluwer Academic Publishers, 27-44.

Price, Derek J. de Solla 1961: Science since Babylon, New Haven, CT:

Rosenberg, Alexander 1986: "Intention and Action Among the Macromolecules," in Current Issues in Teleology, ed. by Nicholas Rescher, Lanham, MD: University Press of America.

Rowe, Stephen 1994: Rediscovering the West. Albany, NY: SUNY Press.

Slade, Francis, 1997: "Ends and Purposes," in Richard F. Hassing ed. Final Causality in Natural and Human Affairs. Washington D.C.: The Catholic University of America Press.

Takakusu 1947: Essentials of Buddhist Philosophy. Honolulu: University of Hawaii Press.

Tenner, Edward 1997: Why Things Bite Back, Technology and the Revenge of Unintended Consequences. New York, NY: Alfred A. Knopf, Inc.

Toffler, Alvin 19?? Future Shock

Urban, G. R. (ed.) 1971: Can We Survive Our Future? — A Symposium, New York: St. Martin's Press.

Valery, Paul 1970: Collected Works, trans. by Roger Shattuck and Frederick Brown, London, 1970. 
Watson, Burton 1964: Chuang Tru, Basic Writings. New York, NY: Columbia University Press.

Wu, Joseph S. 1975: "Causality: Confucianism and Pragmatism." Philosophy East and West, Jan. 1975, 1322.

Xu Fuguan 1966: Zhongguo Yishu Jingshen [The Chinese Aesthetic Spirit]. Taiwan: Zhongyang Shuju.

Zhang Xianglong 1996: Haidegeer Sixiang Yu Zhongguo Tiandao —Zhongï Shiyu De Kaiqi Yu Jiaorong

[Heidegger's Thoughts and the Chinese Dao — The Opening and the Intermingling of the Ultimate Vision]. Beijing, San Lian Shu Dian.

${ }^{1}$ See Ellul, 1964, and Mumford, 1970. Both Ellul and Momford are "pessimists" in the sense that they do not believe that the advancement of technology itself is able to solve the problems related to technology.

2 Heidegger (1997): 4.

${ }^{3}$ Bugliarello and Doner (1979): 138.

${ }^{4}$ Callicott and Ames (1989): 280. The word "technology," though can be traced back to its Greek origin "techne," gains its current meaning in the mid-nineteenth century. See Marx (1994): 17.

${ }^{5}$ Heidegger (1997): 7. I say "loosely" because as Heiddegger points out that even the so-called "efficient cause" in Aristotelian philosophy is not the making of something, but rather the agent who "is co-responsible" with the other three as that from whence the product exists. The agent's contribution is that he "considers carefully and gathers together the three." So the Aristotelian doctrine neither knows the cause that is named by this term nor uses a Greek word that would correspond to it. See ibid. p. 8.

${ }^{6}$ Einstein, in a letter to J.E.Switzer, made the point that the astonishing thing is not that the Chinese sages did not discover experimental method to identify causal relations, it is rather that the discoveries of this kind were made at all. See Price (1961): 15.

7 See Heidegger (1997): 7.

8 Needham (1956): 281-91. See also Cheng (1976): 3-20, and Defroort (1997).

${ }^{9}$ Heidegger (1997): 23.

10 Mitcham (1973): 186.

11 Tenner (1997): xi, 22.

12 Slade (1997): 83-4.

13 See Dawkins (1981): 556-73, and Rosenberg (1986).

14 My translations are based upon Wing-tsit Chan's. See Chan (1963).

15 Tenner (1997): 276.

16 Zhuangzi, in Watson (1964): 91. Again, my reliance on the translation is only to the extent that I think it is accurate.

${ }^{17}$ Heidegger (1997): 23.

18 Ibid., 119-20.

19 Athearn (1994): 11.

${ }^{20}$ Ibid., 116-7.

${ }^{21}$ Bugliarello and Doner (1979): 234.

22 Griffin (1996): 677.

${ }^{23}$ Dallmayr (1996): 146.

${ }^{24}$ See Rowe (1994): 110.

25 See Toffler (1970), part four.

${ }^{26}$ Needham (1956): 281-91. 
${ }^{27}$ Dao De Jing, chpt. 44.

${ }^{28}$ Ibid., chpt. 42.

${ }^{29}$ Ibid., chpt. 30.

30 6:21.

$312: 1$.

${ }^{32}$ See Jung (1950 and 1960). Jung used the word "causality" exclusively to the sequential linkage between events, which rejects the possibility of simultaneous causation off the hand. Yet I think what Jung calls synchronicity is characteristic of the Chinese notion of causation --which can be non-sequential, yet nevertheless causal in the sense that one thing's being responsible for the existence of another that is simultaneous to it, such as the object and its shadow, the momentary situation and its symptoms.

33 Jung (1950): xxiv $\sim$ xxv.

${ }^{34}$ Chapter 2.

${ }^{35}$ Chapter 18.

36 Chapter 16.

${ }^{37}$ Heidegger (1997): 18.

${ }^{38}$ Hassing (1997): 213.

39 Zhuangzi, Book 19, in Watson (1964): 126-7.

${ }^{40} \mathrm{See} \mathrm{Ni}, 1996$, for discussion of the translation and interpretation, and Ni, 1999, for further elaboration.

${ }^{41}$ See, for instance, Dickinson, 1904, and Paul Valery's essay "The Yalu," in Valery (1970). I own my knowledge about these works to Michael Adas's discussion of them in his Machines as the Measure of Men, 348-50.

42 See Ezrahi (1994): 2.

${ }^{43}$ The story is used by Toynbee in an interview. The Roman Emperor's reason was that this kind of invention will put glass-makers of Alexandria out of employment, and lead in turn to riots and revolution, eventually to anarchy. See Urban (1971): 35.

${ }_{44}^{4}$ Takakusu (1947).

${ }^{45}$ Lai (1977): 250.

46 Ibid., 251.

${ }_{47}$ Zhuangzi, chpt. 12.

${ }^{48}$ Laozi, Dao De Jing, ch. 28.

${ }^{49}$ Chan (1963): 407.

${ }^{50}$ See Xu Fuguan (1966).

51 See Zhang Xianglong (1996): 433-6. 